\title{
EXPLORING THE EFFECT OF ORGANIC ADDITIVES ON PHYSICAL PROPERTIES OF BITUMEN
}

Scientific paper

(Received: 19 May 2021; accepted: 19 November 2021)

Noor M. Asmael

Highway and Transportation Department, College of Engineering, Mustansiriyah University, Baghdad, Iraq, Assistant Professor

Corresponding author: noor_moutaz@uomustansiriyah.edu.iq

Mohammed Y. Fattah

Civil Engineering Department, University of Technology, Baghdad, Iraq, Professor

\section{Abdalmhiman Kadhim}

Highway and Transportation Department, College of Engineering, Mustansiriyah University, Baghdad, Iraq

\begin{abstract}
Warm additives had wide popularity in recent years due to saving in energy and lowering emissions dealt with asphalt mixture production. Warm Mix Asphalt (WMA) is produced by using foaming technology or reducing viscosity additives of binder to enhance the rheological properties. In this study, organic-based additives (Asphaltan $A$ and Asphaltan B) are used to investigate their effect to minimize the viscosity and lower the temperature of asphalt mixture production. Bitumen is mixed with three doses of each additive: 1,2 , and $3 \%$ of its weight. The binder viscosity was measured by rotational viscometer with and without the additives at three different temperatures. The study showed that the organic additives have a positive impact on the behavior of the binder in terms of viscosity reduction and made enhancements in terms of bitumen properties. This result could be useful in the reduction of production temperature and quantity of odour emissions.
\end{abstract}

Keywords: Warm mix asphalt; asphaltan a; asphaltan b; bitumen properties; organic additives. 


\section{INTRODUCTION}

Warm-mix asphalt (WMA) was introduced in recent years because of environmentally friendly needs [1]. New technologies utilize products that use mechanical means or additives to reduce the viscosity and shear resistance of bitumen during construction, which reduces temperature with no negative effect on performance.

Hurley and Prowell [2] determined the applicability of processes developed to reduce the mixing and compaction temperatures of Hot mix asphalt (HMA) without sacrificing the quality of the resulting pavement in typical paving operations and environmental conditions, including the performance of the mixes in quick traffic turnover situations and high-temperature conditions. The statistics indicate an overall reduction in air voids. Improved compaction was noted at temperatures as low as $190^{\circ} \mathrm{F}\left(88^{\circ} \mathrm{C}\right)$. The rutting potential increased with decreasing mixing and compaction temperatures, which may be related to the decreased aging of the binder resulting from the lower temperatures. There was no evidence of differing strength gain with time for the mixes containing the three processes compared with the control mixes, indicating that a prolonged cure time before opening to traffic is not an issue. The lower compaction temperature used when producing warm asphalt may increase the potential for moisture damage. Overall, Aspha-min, Sasobit, and Evotherm appear to be viable tools for reducing the mixing and compaction temperatures that can be readily added to hot mix asphalt. Reductions in mixing and compaction temperatures are expected to reduce fuel costs, reduce emissions, widen the winter paving window, and facilitate niche applications, such as airport runway construction, where the rapid opening to traffic is essential.

Behnood [3] stated that WMA includes a series of technologies to mix and compact asphalt mixtures at temperatures lower than the temperatures normally used in the production of hot mix asphalt (mainly by reducing the viscosity of bitumen binders). Different WMA technologies affect the performance of binders and mixtures in different ways. Much has been learned about the WMA technologies used in the pavement industry and their effects on the thermomechanical properties of WMA mixtures and the rheological properties of bitumen binders.

Two silicone-based WMA additives (Tego XP and Addibit) were used by Lushinga et al. [4] to prepare crumb rubber modified (CRM) WMA binders. The viscosities of the CRM binders were measured at different temperatures and shearing rates. Furthermore, softening point and penetration tests, multiple stress creep recovery (MSCR), time sweep, atomic force microscopy, frequency sweep, and Fourier transform infrared (FTIR) tests were also conducted on the prepared samples. FTIR test results confirmed the presence of polydimethylsiloxane (PDMS) in CRM binders with Tego XP and Addibit. PDMS is a well-known hydrophobic organic and inorganic polymer that is water repellent; therefore, binders containing these silicone-based warm-mix additives could be beneficial in resisting moisture damage in bitumen binders and mixtures. The morphology of the CRM binders with and without WMA revealed a good distribution of the rubber particles in the bitumen binder matrix. Further addition of WMA increased the surface roughness of the binder, which can be correlated with changes in the microstructural properties of the binder. Therefore, it was concluded that the addition of Tego XP and Addibit reduced the viscosity and improved the mechanical properties of the bitumen binder.

Wang et al. [5] investigated the high-, intermediate-, and low-temperature performances of CRM bitumen binders containing WMA additives. The asphalt-rubber interactions under various mixing combinations of temperature and time were investigated using microscopic and mechanical methods to obtain the optimal mixing procedure. The effects of WMA additives (wax-based and chemical-based products) on the binder performance were investigated using MSCR, linear amplitude sweep, and low-temperature frequency sweep tests. The results showed that rubberized bitumen binders significantly improved the binder performance of the base bitumen in different temperature ranges. The effects of WMA additives on the binder performance varied with the base bitumen and rubberized bitumen binder. In addition, the nonrecoverable compliance difference was found to be unsuitable for characterizing the stress sensitivity of rubberized binders, and the difference in the nonrecoverable compliance for an incremental change in applied stress was proved to be a more accurate alternative.

The effect of the recycling method on the overall service performance of warm crumb rubber modified asphalt mixtures (WCRMAs) was characterized by Yu et al. [6]. A fuzzy comprehensive evaluation (FCE) method was employed to quantify the performance grade of the asphalt mixtures according to fuzzy logic. The weight matrix of all the service properties was developed based on the analytic hierarchy process considering the circumstances of southern China. The experimental work revealed the significant influence of the recycling method on the service performance of WCRMAs. The results of this study using the FCE method suggested that, for southern China, with 
a hot and humid climate, the optimal method of recycling crumb rubber into wax-based WCRMA is mixing asphaltrubber (AR) and Sasobit first and then incorporating them into aggregate. In rainy regions, asphalt mixtures produced by directly mixing AR, Sasobit, and aggregate at $160^{\circ} \mathrm{C}$ may perform better because they show the best moisture damage resistance and good overall performance.

Waste cooking oil (WCO) was used by Li et al. [7] as a WMA additive to modify warm-mix epoxy asphalt binder (WEAB) with the expectation of lowering the viscosity and prolonging the construction time of the binder. The viscosity, phase separation, viscoelasticity, thermostability, and mechanical properties of WCO-modified WEABs were studied and compared with those of neat WEAB. WCO significantly reduced the viscosity of the WEAB and extended the construction time of the neat WEAB. Moreover, the reducing and prolonging effects increased with increasing WCO content. A phase-inverted microstructure and secondary phase separation formed in the modified WEAB with 6-wt \% WCO. The inclusion of WCO improved the low-temperature performance of the neat WEAB. The damping behavior and thermostability of neat WEAB improved with the inclusion of WCO. The presence of WCO increased the elongation at the break of the neat WEAB when the waste oil content was lower than $4 \mathrm{wt} \%$.

Various warm mixtures have been evaluated extensively in recent years, but few studies have been conducted to explore the effect of organic warm additives, especially Asphaltan $A$ and Asphaltan $B$, on bitumen properties. The main objective of this study was to determine how organic additives can affect the bitumen properties and determine the effects of additive type and content on the properties of bitumen.

\section{MATERIALS}

\subsection{Bitumen}

The bitumen used in this study was 40/50 penetration grade supplied by the Daurah refinery plant in Baghdad, Iraq. The physical properties of the bitumen samples are listed in Table 1.

Table $140 / 50$ bitumen properties

\begin{tabular}{cccc}
\hline Properties & Unit & Test Result & Test Method \\
\hline Penetration at $25{ }^{\circ} \mathrm{C}$ & $\mathrm{dmm}$ & 41 & ASTM D5/D5M - 13 \\
Ductility at $25{ }^{\circ} \mathrm{C}$ & $\mathrm{cm}$ & $>100$ & ASTM D113 - 07 \\
Specific gravity at $15.6{ }^{\circ} \mathrm{C}$ & & 1.04 & ASTM D70 - 09 \\
Flash point & ${ }^{\circ} \mathrm{C}$ & 326 & ASTM D22 - 72 \\
Softening point & ${ }^{\circ} \mathrm{C}$ & 51.5 & ASTM D36/D36M - 14 \\
Percentage of weight soluble in $\mathrm{C}_{2} \mathrm{HCL}_{3}$ & $(\%)$ & 0.999 & ASTM D2042 - 15 \\
\hline
\end{tabular}

\subsection{Warm-mix additives}

One WMA technology was studied in this research. The organic additives Asphaltan A and Asphaltan B, manufactured by Romonta Company, were used, as shown in Figure 1. Asphaltan A and Asphaltan B are Montan wax added to a fatty acid after refining. The Montan wax combination consists of nonglyceride long-chain carboxylic acid esters, long-chain alcohols, and free long-chain organic acids, and it is a fossilized plant wax. These additives had a light brown color and a weak specific odor, and they were available in a pastille form (1-3 mm in diameter). The two additives were incorporated at three different percentages-1 $\%, 2 \%$, and $3 \%$ by weight - of the binder. The physical properties of the additives are listed in Table 2 . The point at which melting occurs is $80-95^{\circ} \mathrm{C}[8]$. 


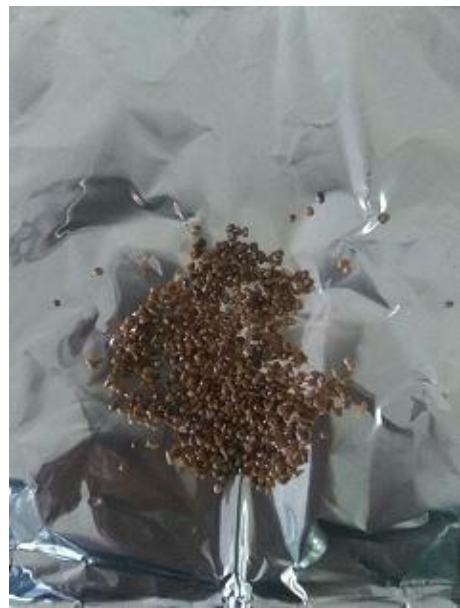

(a) Picture of Asphaltan A

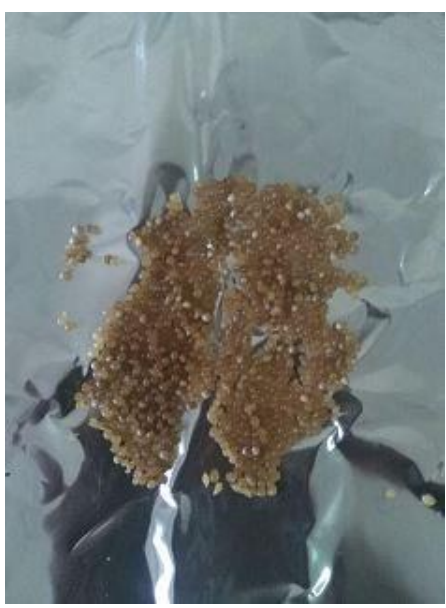

(b) Picture of Asphaltan B

Figure 1 Warm additives used in the study

Table 2 Warm additive physical properties

\begin{tabular}{ccccc}
\hline Additive type & $\begin{array}{c}\text { Solidification point } \\
{\left[{ }^{\circ} \mathrm{C}\right]}\end{array}$ & $\begin{array}{c}\text { Flash point } \\
{\left[{ }^{\circ} \mathrm{C}\right]}\end{array}$ & $\begin{array}{c}\text { Ignition temperature } \\
{\left[{ }^{\circ} \mathrm{C}\right]}\end{array}$ & Viscosity, mPa.s \\
\hline Asphaltan A & $133-143$ & $>200$ & $>300$ & $5-15$ at $150{ }^{\circ} \mathrm{C}$ \\
Asphaltan B & $95-105$ & $>250$ & $>300$ & $20-200$ at $120^{\circ} \mathrm{C}$ \\
\hline
\end{tabular}

\section{MODIFIED BINDER}

Three dosages of additives were used-1 $\%, 2 \%$, and $3 \%$ by weight of virgin bitumen-to prepare the modified binder. These additives were added to the bitumen. A mixer with a propeller and steel container was used to produce the modified binders. The virgin binder was heated at $150^{\circ} \mathrm{C}$ and poured into a preheated steel container. The additives were added carefully to the virgin binder as quickly as possible and mixed for 10, 20, and 30 min at $120 \mathrm{rpm}$ so that the entire additive dosage melted into the binder. The modified binder was then removed and left to cool at room temperature.

\section{RESULTS AND DISCUSSION}

\subsection{Effect of organic warm additive on mixing and compaction temperature}

Viscosity describes the resistance of the fluid to the flow. To test the suitability of bitumen for pumping during construction and to ensure the coating of aggregates at the mixing units, it is necessary to observe the viscosity of the binder. The viscosity values obtained through the rotational viscometer test method according to AASHTO T 316-13 [9] were used to determine the mixing and compaction temperatures of HMA. The viscosity of the binder changes with the change of additive type and content, as shown in Table 3 and Figure 2. The average mixing and compaction temperature ranges for the unmodified binder are $163.5-164.0^{\circ} \mathrm{C}$ and $152.8-153.4^{\circ} \mathrm{C}$, respectively. Figure 2 shows that the viscosity of the modified binder is less than that of the virgin binder at all tested temperatures. The warm additives decrease the mixing and compaction temperature by $10^{\circ} \mathrm{C}$. The noticeable decrement makes it possible to predict the impact of additives, but this is not within the specified temperature range of WMA. Therefore, the production temperature of warm mixtures is based on the recommendations of the suppliers 
of Romonta Company. Table 4 shows the mixing and compaction temperatures, and Figure 3 shows the viscosity parameters of the control and modified binders.

Table 3 Rotational viscosity for virgin and modified binder

\begin{tabular}{ccccc}
\hline & \multicolumn{3}{c}{ Temperature $\left[{ }^{\circ} \mathrm{C}\right]$} \\
Sample & 110 & $\begin{array}{c}135 \\
\text { Viscosity, Pa.s }\end{array}$ & 165 & Sample Code \\
\hline Control & 2.491 & 0.656 & 0.160 & Base bitumen \\
A1 & 1.881 & 0.381 & 0.108 & Bitumen modified with 1\% Asphaltan A \\
A2 & 2.386 & 0.336 & 0.105 & Bitumen modified with 2\% Asphaltan A \\
A3 & 2.070 & 0.379 & 0.104 & Bitumen modified with 3\% Asphaltan A \\
B1 & 1.776 & 0.367 & 0.106 & Bitumen modified with 1\% Asphaltan B \\
B2 & 1.540 & 0.321 & 0.100 & Bitumen modified with 2\% Asphaltan B \\
B3 & 1.716 & 0.355 & 0.103 & Bitumen modified with 3\% Asphaltan B \\
\hline
\end{tabular}

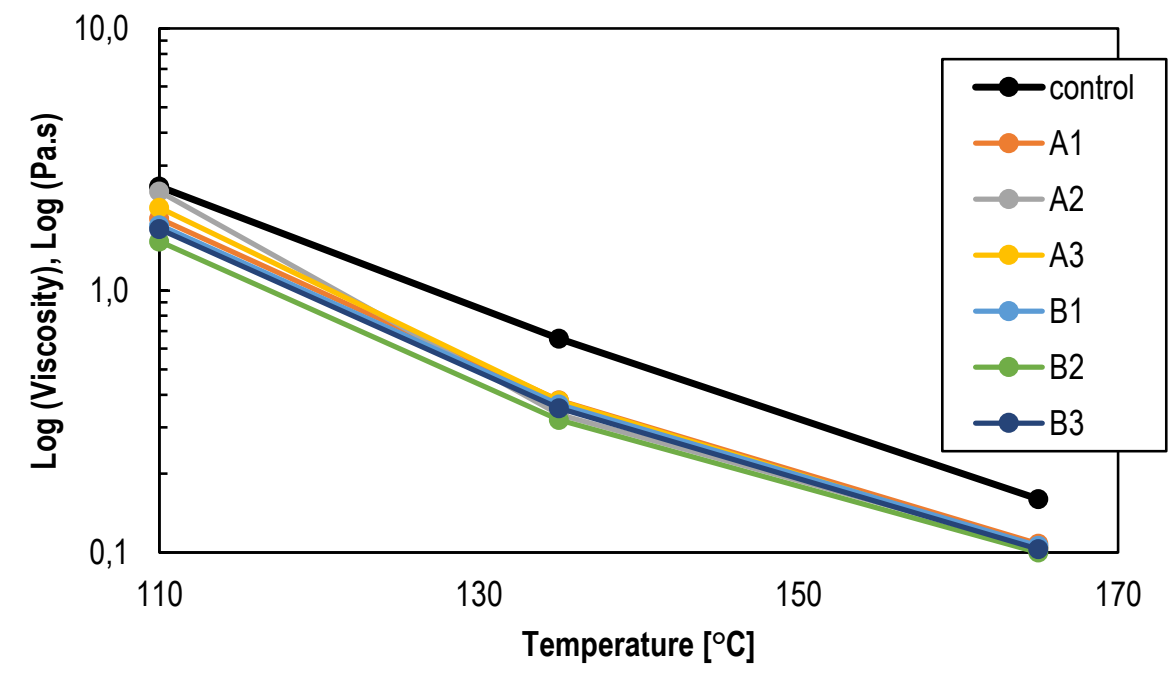

Figure 2 Viscosities with different percentages of each additive

Table 4 Mixing and compaction temperature according to the Asphalt Institute graph.

\begin{tabular}{ccccc}
\hline Mix ID & \multicolumn{2}{c}{ Mixing } & \multicolumn{2}{c}{ Comperature $\left[^{\circ} \mathrm{C}\right]$} \\
& from & to & from & to \\
\hline Control & 161 & 164 & 150 & 154 \\
A1 & 151 & 154 & 139 & 144 \\
A2 & 149 & 153 & 136 & 141 \\
A3 & 151 & 154 & 139 & 144 \\
B1 & 151 & 154 & 139 & 144 \\
B2 & 148 & 152 & 135 & 140 \\
B3 & 150 & 153 & 137 & 142 \\
\hline \hline
\end{tabular}

Asmael, N, Fattah, M, Kadhim, A 


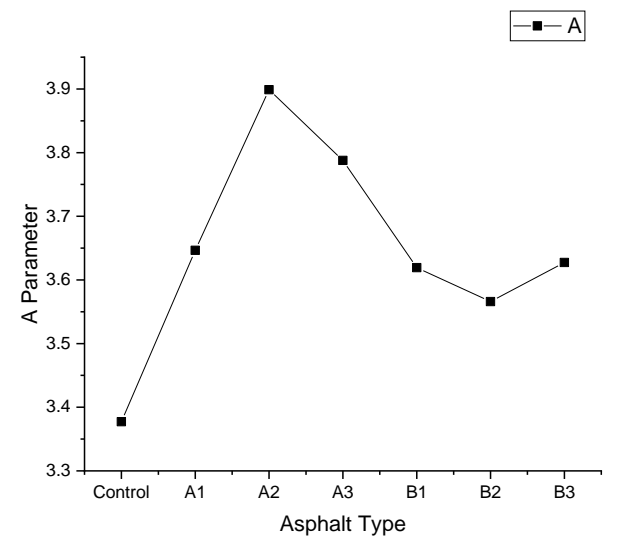

(a) A parameter

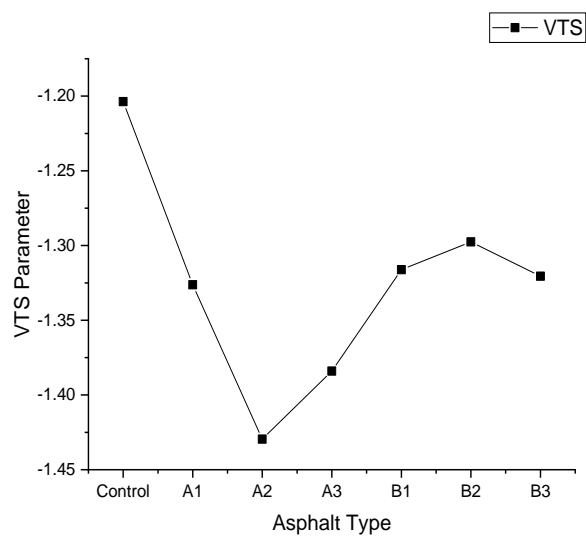

(b) VTS parameter

Figure 3 Viscosity parameters

In step 10 of its special mix design considerations for WMA, NCHRP report 714 [10] noted that viscosity-based mixing and compaction temperatures are not used for WMA mixtures [11] and [12]. The report recommended that mixing and compaction of WMA mixtures must be carried out at the planned production temperature. The Asphaltan $A$ and Asphaltan B supplier, Romonta Company, reported that temperatures for plant mixing should be as low as $120^{\circ} \mathrm{C}$. Based on the available information, WMA mixing and compaction temperatures must be within $120^{\circ} \mathrm{C}$ and $110^{\circ} \mathrm{C}$, respectively.

\subsection{Effect of mixing time on the physical properties of bitumen}

Samples of properly mixed bitumen with different percentages of additives were prepared. The heating process was performed for bitumen to obtain a flowing state at $150^{\circ} \mathrm{C}$. Then, each additive was poured into the bitumen separately and mixed using an electric mixer at $120 \mathrm{rpm}$. The mixing was performed for three different times-10, 20 , and 30 min - to determine the best mixing conditions. Subsequently, penetration, ductility, and softening point were examined. A ductility test was conducted at $25^{\circ} \mathrm{C}$, and the results were more than $100 \mathrm{~cm}$ for each specimen. The effects of mixing on the penetration and softening point test results are shown in Figure 4 . The optimal mixing time was found to be $10 \mathrm{~min}$.

The effects of adding a dosage of $2 \%$ by weight of each additive to the virgin binder properties (penetration and softening point) are illustrated in Figure 4 . A mixing time of 10 min was sufficient to produce a modified binder. Mixing for 20 and 30 min was a waste of time and energy, producing a modified binder with properties equal to those after a 10-min production time. It was clear that Asphaltan A and Asphaltan B played a role in increasing the softening point and enhancing the flow. This finding was proved by Edwards et al. [13] who studied the effects of Sasobit and Asphaltan A. Figure 5 illustrates the percent difference in the penetration and softening point of the modified binder with respect to virgin versus mixing times. 

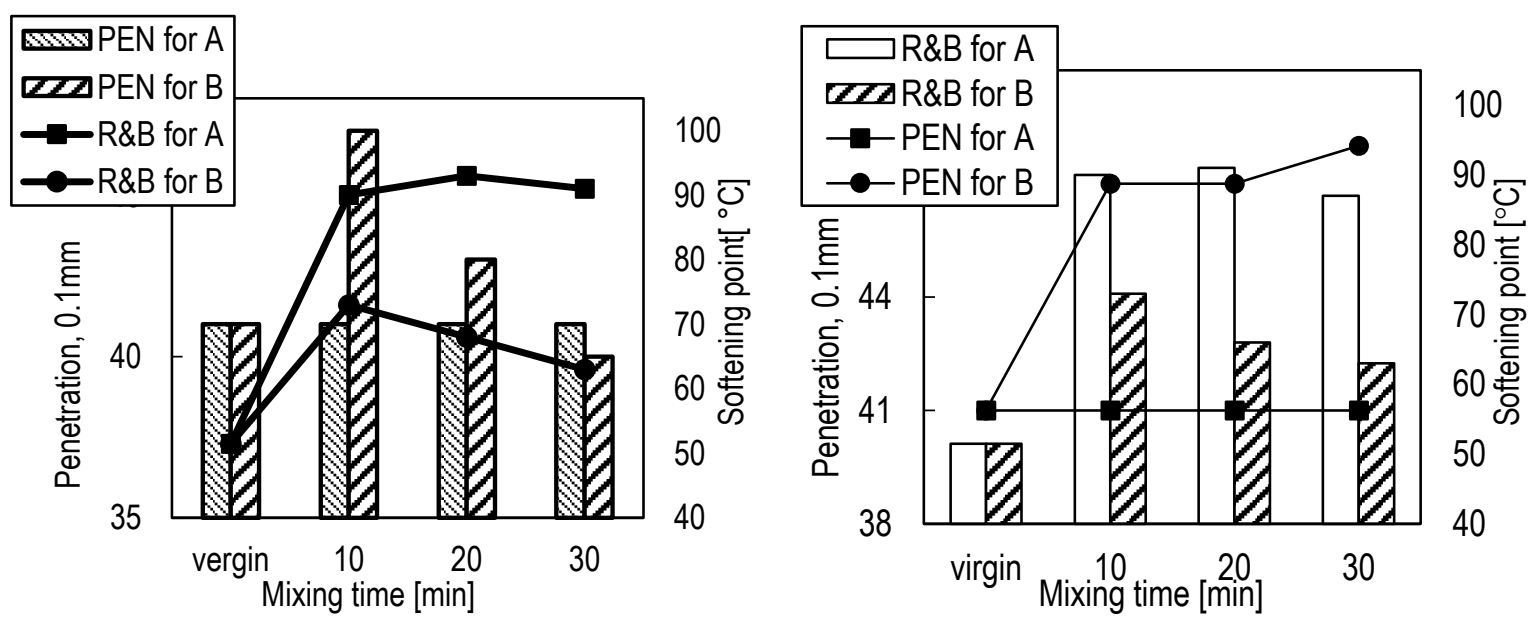

Figure 4 Penetration and softening point results for virgin and modified binder (R\&B: ring and ball test, PEN: penetration test, A: Asphaltan A, B: Asphaltan B)

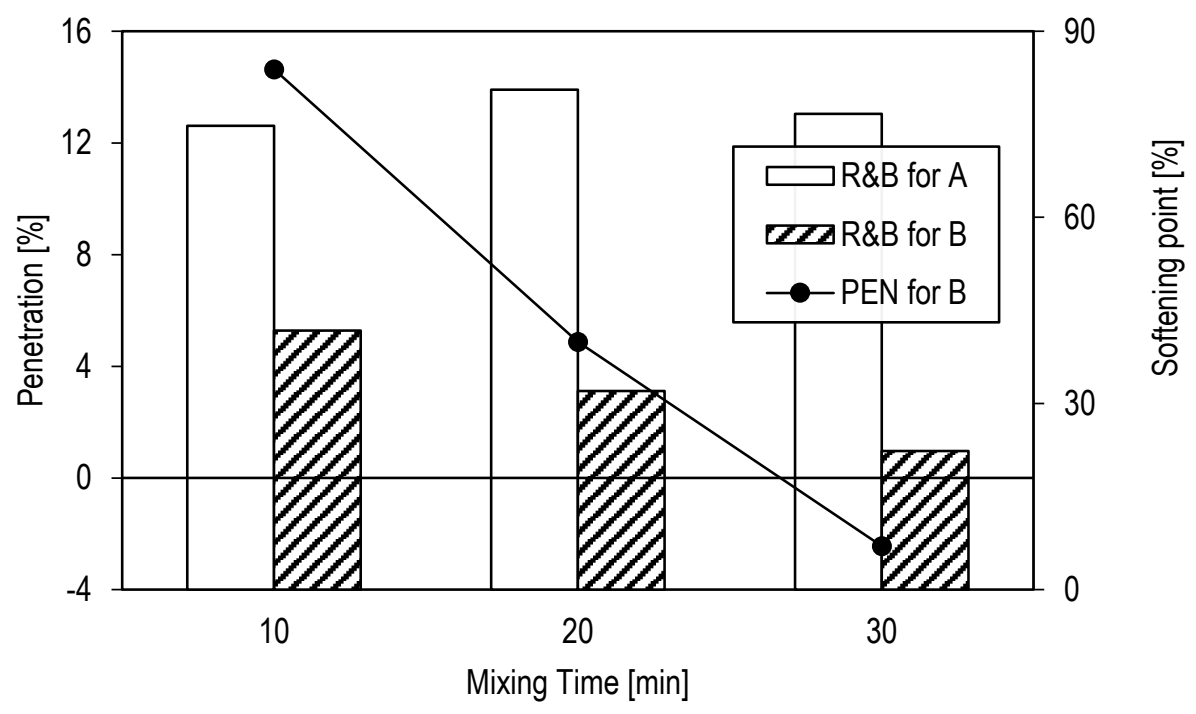

Figure 5 Percentages of penetration and softening point versus mixing time for $2 \%$ of additive

Figures (6-8) illustrate the effect of the additive content on the physical properties of bitumen. The penetration and softening point values at different concentrations of Asphaltan $A$ and Asphaltan B are illustrated in Figure which shows that $1 \%$ of Asphaltan $B$ leads to a significant increase in penetration value for the virgin binder. The gradual decrease in penetration values occurs with higher doses of Asphaltan B. No difference was observed in the penetration values of the binders modified with Asphaltan $A$. These results demonstrate that such binders resist permanent deformation at moderate and elevated temperatures. Figure shows the percent difference of penetration and softening point of the modified binder with respect to virgin versus additive content. The high melting points of the modified binder indicate the tendency of the binder to flow at such high temperatures. The increase in penetration indicates the possibility of manufacturing temperature reduction, as proved by Rodríguez-Alloza et al. (2014) [14].

The penetration index $(\mathrm{PI})$ is a measure of the sensitivity of the binder to temperature fluctuations, and its behavior can be predicted [11]. The PI values are calculated from the measured penetration and softening point temperatures. The calculated PI values are shown in Figure. The values of PI range from approximately -3 (highly temperature susceptible bitumen) to high-PI bitumen around +7 (highly blown low temperature susceptibility) [11]. 
In this study, the PI provided an approximation of the expected temperature sensitivity behavior of bitumen binders. The lower the $\mathrm{PI}$, the higher the temperature susceptibility. Bitumen binders with a PI of less than -2 are more susceptible to temperature and show more brittleness at low temperatures, resulting in a higher susceptibility to thermal cracking [15]. In comparison with the virgin binder, the PI results of the modified binder significantly increase with the increase in the content of the two WMA additives.

However, this indicates that the low temperature susceptibility of the bitumen binder was adversely affected by the addition of Asphaltan A and Asphaltan B. The results proved that the modified binder is highly sensitive to low temperatures, which results in low-temperature cracks and less permanent deformation during summer.

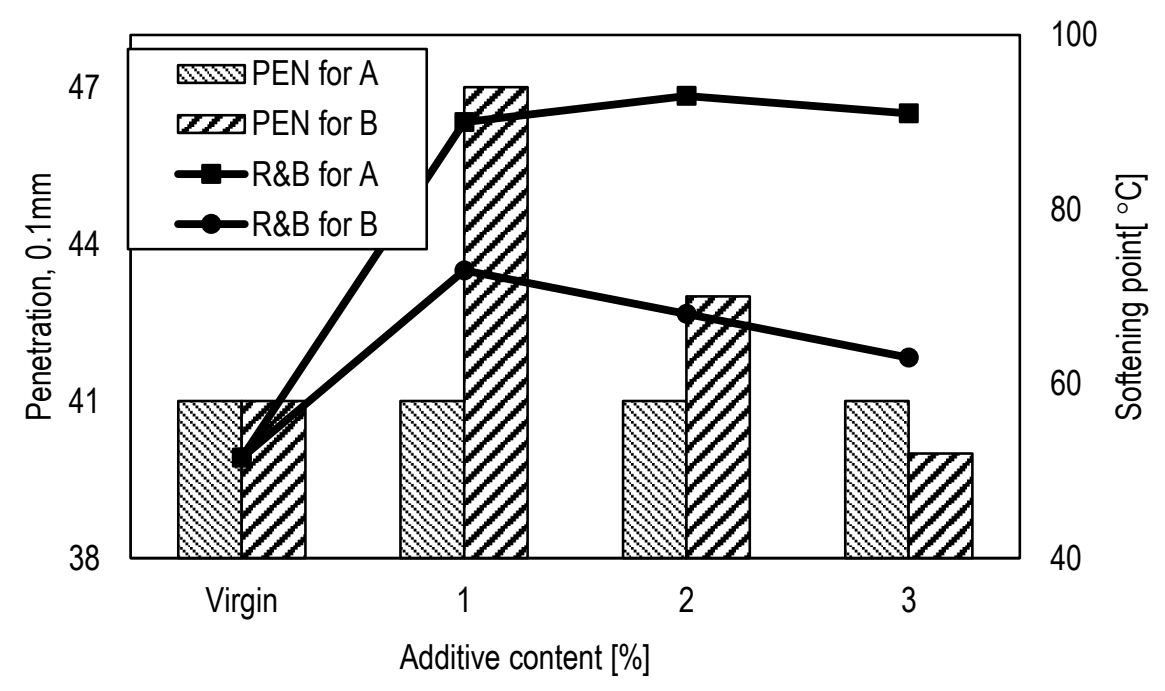

Figure 6 Penetration and softening point values at different concentrations of Asphaltan A and Asphaltan B

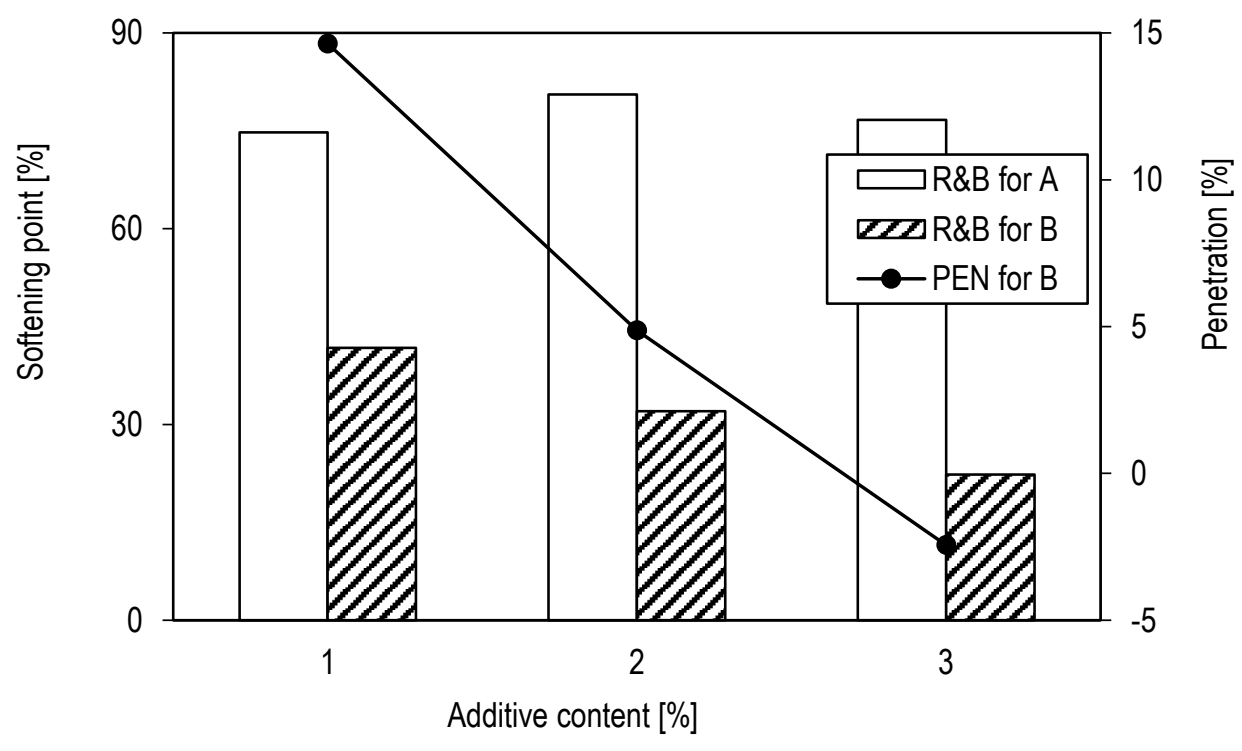

Figure 7 Percentage of penetration and softening point versus additive content 


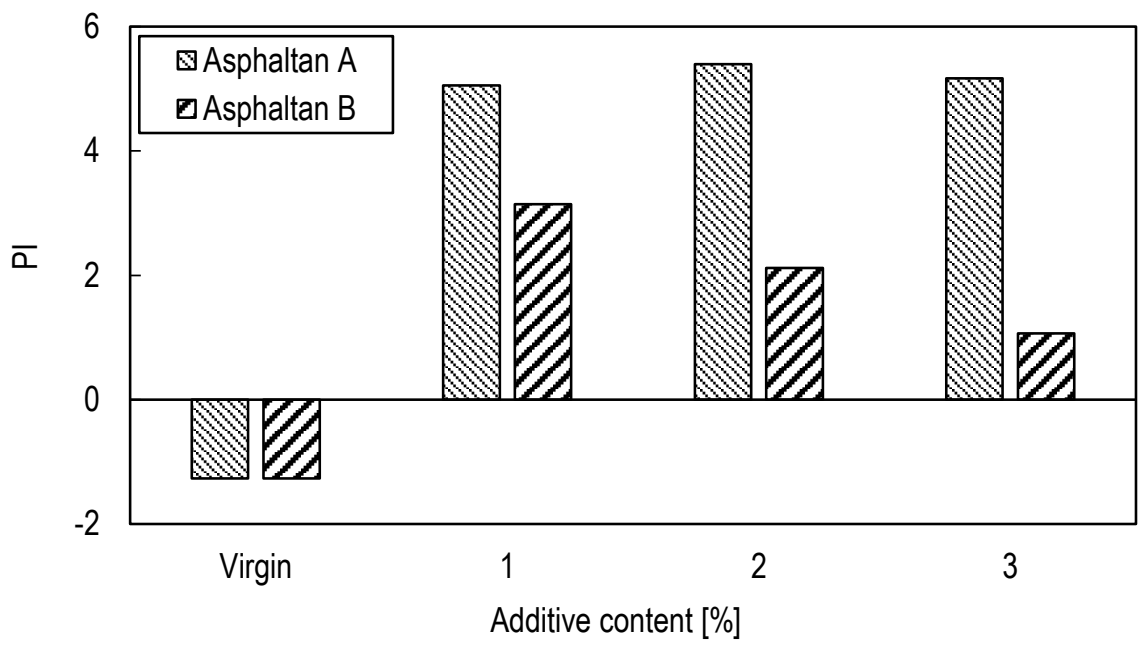

Figure 8 Penetration index of virgin binder and modified binder with different concentrations of additives.

Two mixes with hot mix asphalt were compacted and tested. The SC mix code refers to hot mix asphalt with a surface mix, and BC refers to hot mix asphalt with the base mix.Warm asphalt mixtures were compacted for two mixes: one for the surface course and the other for the base course with two additives. Stiffness was measured for all mixtures, and the results are shown in Figures 9 and 10. The code for the mix is as follows. The first letter refers to the mix type: $S$ is the surface course, and $B$ is the base course. The second letter refers to the additive type: $A$ is Asphaltan $A$, and $B$ is Asphaltan $B$. The third code refers to the doses of additive used: $1 \%, 2 \%$, and $3 \%$. Example: SA1 refers to surface course mix modified with $1 \%$ Asphaltan $A$.
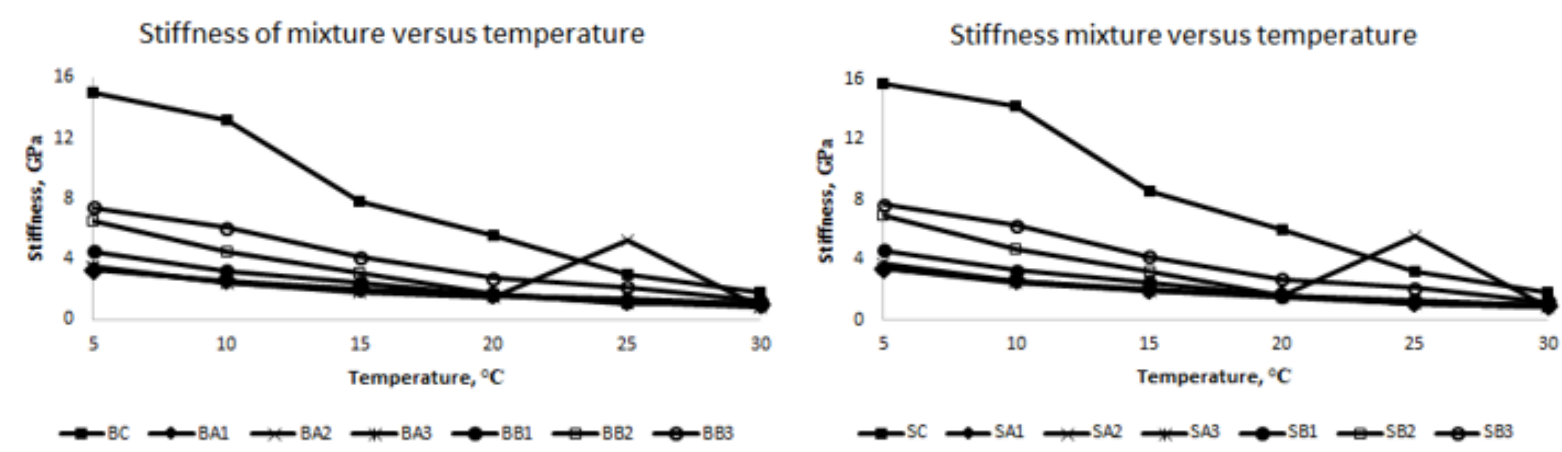

Stiffness of binder versus temperature

Stiffness binder versus temperature
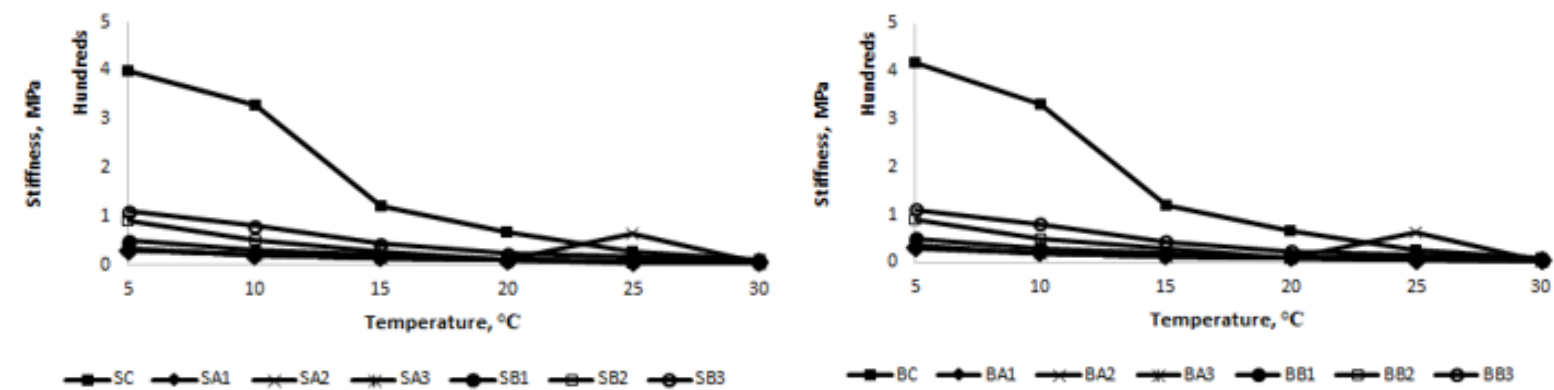

Figure 9 Stiffness of binder and mixture under different temperatures

Asmael, N, Fattah, M, Kadhim, A 
Figure 9 shows that the base mixture has high stiffness values compared with other mixtures prepared by organic additives, and mixtures prepared with Asphaltan $B$ additive show higher values of stiffness after the addition of the base mixture. As the percentage of the additive increases, the stiffness increases. It appears that mixtures prepared with Asphaltan A show a similar trend of stiffness values for all percentage values. In addition, as the temperature increases, the stiffness of the mixture and binder decreases.

Complex modulus versus temperature, $\mathrm{f}=10 \mathrm{~Hz}$

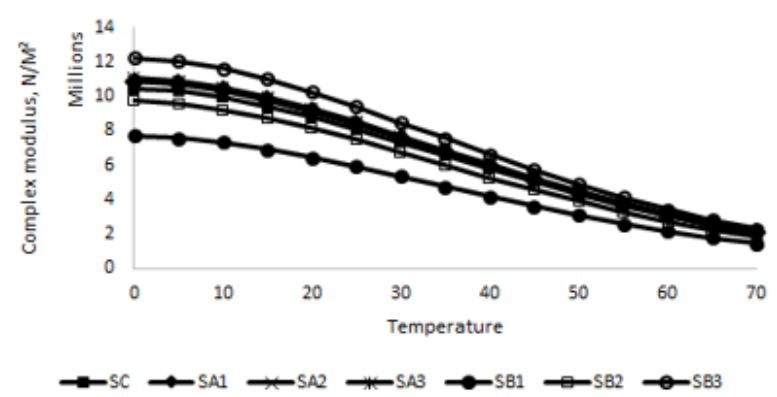

Complex modulus versus temperature, $\mathrm{f}=4 \mathrm{~Hz}$

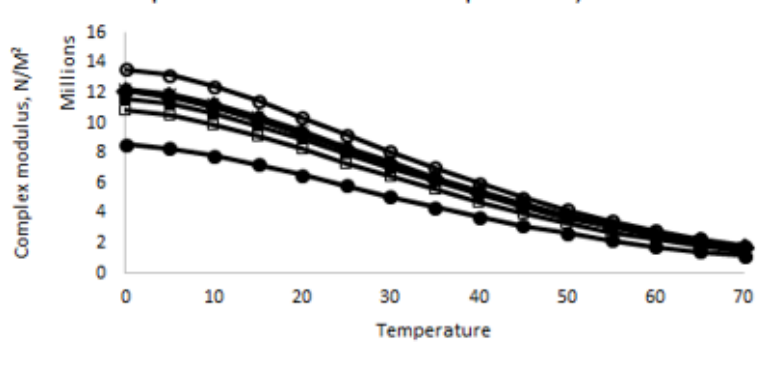

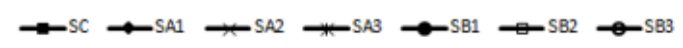

Complex modulus versus temperature, $\mathrm{f}=8 \mathrm{~Hz}$

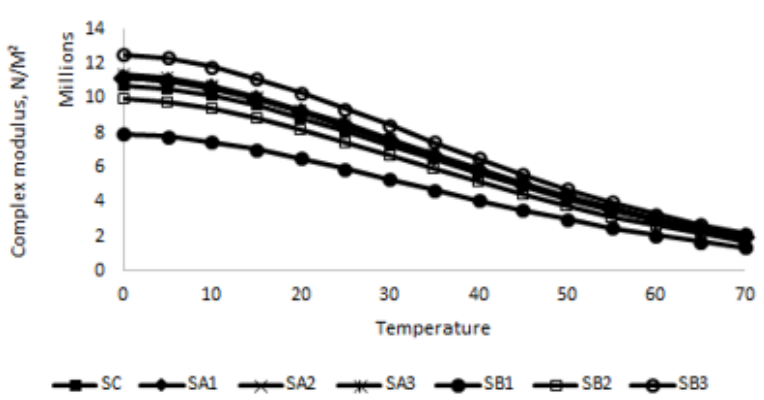

Complex modulus versus temperature, $\mathrm{f}=6 \mathrm{~Hz}$

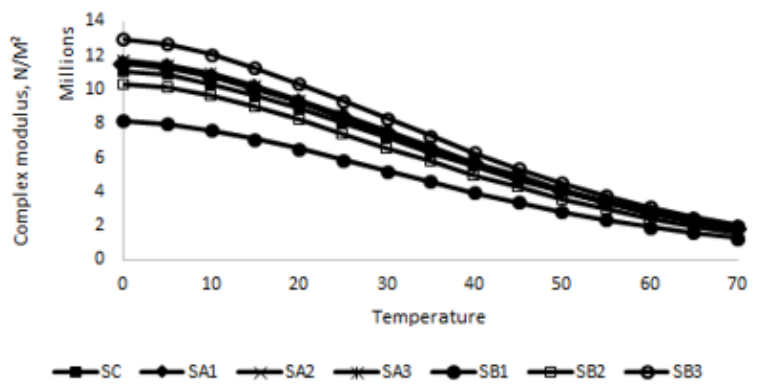

Complex modulus versus temperature, $\mathrm{f}=10 \mathrm{~Hz}$

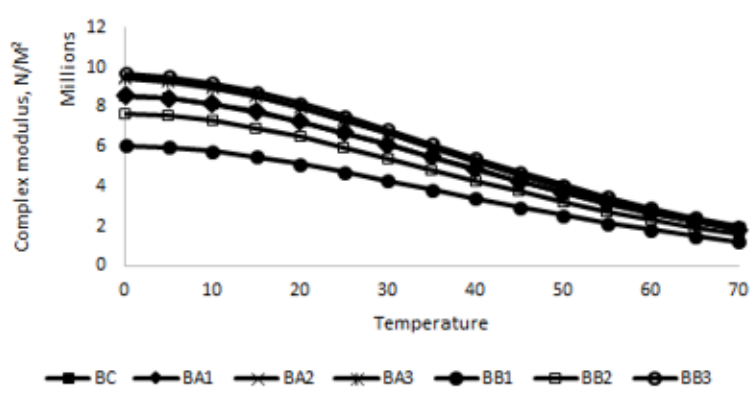

Complex modulus versus temperature, $\mathrm{f}=4 \mathrm{~Hz}$

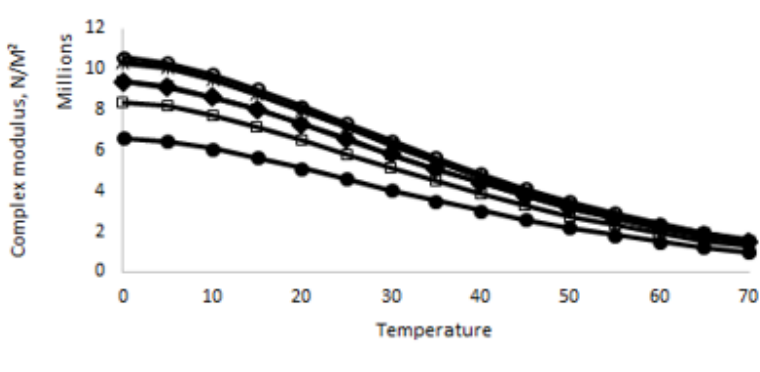

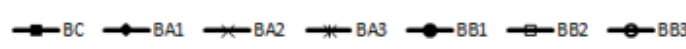

Complex modulus versus temperature, $\mathrm{f}=8 \mathrm{~Hz}$

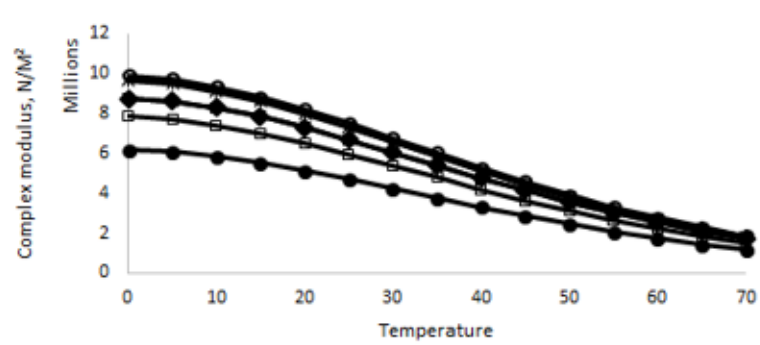

$\rightarrow B C \rightarrow B A 1 \rightarrow B A 2 \longrightarrow B A 3 \rightarrow B B 1 \rightarrow B 82 \rightarrow B B 3$

Complex modulus versus temperature, $\mathrm{f}=6 \mathrm{~Hz}$

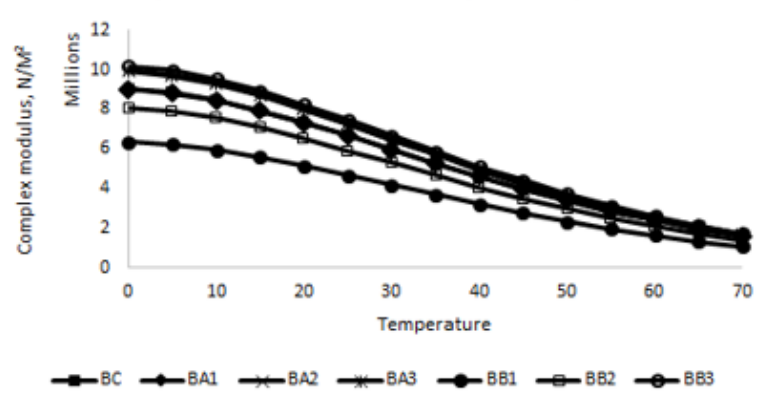

Figure 10 Complex modulus of different mixtures with different temperatures

Asmael, N, Fattah, M, Kadhim, A 


\section{CONCLUSIONS}

The main conclusions of this study are as follows.

1. Organic additives have a positive impact on the behavior of binders in terms of viscosity reduction, as well as enhancements in terms of the properties of bitumen.

2. Organic additives should be useful in reducing the production temperature and quantity of odor emissions.

3. The warm additives decreased the mixing and compaction temperature by $10^{\circ} \mathrm{C}$, and the noticeable decrease made it possible to predict the impact of additives.

4. Asphaltan $A$ and Asphaltan $B$ played a role in increasing the softening point and enhancing the resistance to flow.

5. Mixtures prepared with Asphaltan B provide higher stiffness than mixtures prepared with Asphaltan A.

6. Organic additives decrease the stiffness values of the base mixture, and the stiffness values decrease as the temperature increases.

\section{Data availability statement}

All data, models, and codes generated or used during the study appear in the submitted article.

\section{Acknowledgment}

Mustansiriyah University (www.uomustansiriyah.edu.iq), Baghdad, Iraq, and Romonta Company provided significantly appreciated support for this research.

\section{References}

[1] Brown, D. C. 2008: Warm Mix: the lights are green, HMAT: Hot Mix Asphalt Technology, 13 (1).

[2] Hurley, G. C.; Prowell, B. D.; Reinke, G. 2006: Evaluation of potential processes for use in warm mix asphalt, Journal of the Association of Asphalt Paving Technologists, 75 (4).

[3] Behnood, A. 2020: A review of the warm mix asphalt (WMA) technologies: Effects on thermo-mechanical and rheological properties, Journal of Cleaner Production, 259, 120817. https://doi.org/10.1016/i.jclepro.2020.120817

[4] Lushinga, N. et al. 2020: Performance Evaluation of Crumb Rubber Asphalt Modified with Silicone-Based Warm Mix Additives, Advances in Civil Engineering. https://doi.org/10.1155/2020/4840825

[5] Wang, H. et al. 2020: Asphalt-rubber interaction and performance evaluation of rubberised asphalt binders containing non-foaming warm-mix additives, Road Materials and Pavement Design, 21, pp. 1612-1633. https://doi.org/10.1080/14680629.2018.1561380

[6] Yu, H. et al. 2020: Decision support for selecting optimal method of recycling waste tire rubber into wax-based warm mix asphalt based on fuzzy comprehensive evaluation, Journal of Cleaner Production, 265, 121781. https://doi.org/10.1016/i.jclepro.2020.121781

[7] Li, C. et al. 2020: Impact of waste cooking oil on the viscosity, microstructure and mechanical performance of warm-mix epoxy asphalt binder, Construction and Building Materials, 251, 118994. https://doi.org/10.1016/i.conbuildmat.2020.118994

[8] Malladi, H. 2012: Laboratory Evaluation of Warm Mix Asphalt Technologies for Moisture and Rutting Susceptibility.

[9] American Association of State Highway and Transportation Officials 2016: Standard Specifications for Transportation Materials and Methods of Sampling and Testing and AASHTO Provisional Standards.

[10] Advanced Asphalt Technologies, L.L.C. 2012: Special Mixture Design Considerations and Methods for Warm Mix Asphalt: A Supplement to NCHRP Report 673, A Manual for Design of Hot Mix Asphalt with Commentary, Transportation Research Board.

[11] Read, J.; Whiteoak, D.; Hunter, R. N. 2003: The shell bitumen handbook, 5th Edition, Thomas Telford.

Asmael, N, Fattah, M, Kadhim, A 
[12] Goh, S. W.; You, Z.; Van Dam, T. J. 2007: Laboratory evaluation and pavement design for warm mix asphalt, In Proceedings of the 2007 Mid-Continent transportation research symposium, pp. 1-11.

[13] Edwards, Y.; Tasdemir, Y.; Butt, A. A. 2010: Energy saving and environmental friendly wax concept for polymer modified mastic asphalt, Materials and Structures, 43, pp. 123-131. https://doi.org/10.1617/s11527010-9603-y

[14] Rodríguez-Alloza, A. M. et al. 2014: High and low temperature properties of crumb rubber modified binders containing warm mix asphalt additives, Construction and Building Materials, 53, pp. 460-466. https://doi.org/10.1016/i.conbuildmat.2013.12.026

[15] Anderson, D. A. et al. 1990: Asphalt behavior at low service temperatures, FHWA-RD-88-078, FHWA, U.S. Department of Transportation, Washington, D.C., USA.

Please cite this article as: Asmael, N., Fattah, M., Kadhim, A.: Exploring the Effect of Organic Additives on Physical Properties of Bitumen, Electronic Journal of the Faculty of Civil Engineering Osijek-e-GFOS, 2021, 23, pp. 49-60, https://doi.org/10.13167/2021.23.5 